\title{
CONSTRUCTION OF A BIOENGINEERED CARDIAC GRAFT
}

Ren-Ke Li, MD, PhD

Terrence M. Yau, MD, MSc

Richard D. Weisel, MD

Donald A. G. Mickle, MD

Tetsuro Sakai, MD

Angel Choi, MSc

Zhi-Qiang Jia, MD
Objectives: Currently available graft materials for repair of congenital heart defects cause significant morbidity and mortality because of their lack of growth potential. An autologous cell-seeded graft may improve patient outcomes. We report our initial experience with the construction of a biodegradable graft seeded with cultured rat or human cells and identify their 3-dimensional growth characteristics. Methods: Fetal rat ventricular cardiomyocytes, stomach smooth muscle cells, skin fibroblasts, and adult human atrial and ventricular cardiomyocytes were isolated and cultured in vitro. These cells were injected into or laid onto biodegradable gelatin meshes, and their rate of proliferation and spatial location within the mesh was evaluated by using a cell counter and histologic analysis. Results: Rat cardiomyocytes, smooth muscle cells, and fibroblasts demonstrated steady proliferation over 3 to 4 weeks. The gelatin mesh was slowly degraded, but this process was most rapid after seeding with fibroblasts. Human atrial cardiomyocytes proliferated within the gelatin meshes but at a slower rate than that of fetal rat cardiomyocytes. Human ventricular cardiomyocytes survived within the gelatin mesh matrix but did not increase in number during the 2 -week duration of evaluation. Grafts seeded with rat ventricular cells exhibited spontaneous rhythmic contractility. All cell types preferentially migrated to the uppermost surface of each graft and formed a 300- to 500- $\mu \mathrm{m}$ thick layer. Conclusions: Fetal rat ventricular cardiomyocytes, gastric smooth muscle cells, skin fibroblasts, and adult human atrial cardiomyocytes can grow in a 3-dimensional pattern within a biodegradable gelatin mesh. Similar autologous cell-seeded constructs may eventually be applied to repair congenital heart defects. (J Thorac Cardiovasc Surg 2000;119:368-75)
$\mathrm{C}$ ongenital heart disease is an ongoing problem of significant dimension, affecting approximately $1 \%$ of infants. ${ }^{1}$ Surgical palliation or correction of these defects may require patch reconstruction of stenotic lesions or conduit placement for complex congenital lesions. ${ }^{2}$ However, all currently available grafts are subject to material-related failure, ${ }^{3}$ which is a major contributor to the ongoing morbidity and mortality associated with a diagnosis of congenital heart disease. The

From the Division of Cardiovascular Surgery, Toronto General Hospital, University Health Network, Department of Surgery, University of Toronto, Toronto, Ontario, Canada.

Supported by research grants to R.K.L. from the Medical Research Council of Canada (MT-13665) and The Hospital for Sick Children Foundation (XG 98-063). R.K.L. is a Research Scholar of the Heart and Stroke Foundation of Canada. R.D.W. is a Career Investigator of the Heart and Stroke Foundation of Ontario. The authors are working in partnership with Genzyme Corp.

Read at the Seventy-ninth Annual Meeting of The American Association for Thoracic Surgery, New Orleans, La, April 18-21, 1999. most significant limitation of these grafts is the complete lack of growth potential of all available patch and conduit materials. Lesser, but still significant, factors are their lack of contractility and thrombogenicity.

A viable, autologous, contractile, and less thrombogenic bioengineered tissue graft would be ideal for the surgical repair of congenital cardiac defects. Implanted as a substitute for the wall of a cardiac chamber or an artery, the graft should be able to grow and remodel

Received for publication April 22, 1999; revisions requested June 15, 1999; revisions received Oct 19, 1999; accepted for publication Oct 19, 1999.

Address for reprints: Ren-Ke $\mathrm{Li}, \mathrm{MD}, \mathrm{PhD}$, Toronto General Hospital, CCRW 1-815, 200 Elizabeth St, Toronto, Ontario, M5G 2C4 Canada (E-mail: Renki.Li@uhn.on.ca).

Copyright @ $\odot 2000$ by Mosby, Inc.

$0022-5223 / 2000 \$ 12.00+0 \quad \mathbf{1 2 / 6 / 1 0 3 7 2 8}$ 
with the growth of the child. These tissue-engineered grafts have the potential to reduce morbidity and mortality rates and improve the quality of life of children with congenital heart disease. We have previously reported our experience with the creation of a fetal rat cardiomyocyte-seeded biodegradable gelatin mesh and its in vitro and in vivo characteristics after implantation into the subcutaneous tissue or onto the left ventricular free wall of adult rats. ${ }^{4}$ However, construction of these grafts can be a difficult and time-consuming process, and the optimal combination of cell types and technique of seeding for construction of these grafts is unknown.

We report our initial experience with construction of a cell-seeded biodegradable polymer scaffold by using fetal rat ventricular cardiomyocytes, smooth muscle cells and fibroblasts, and adult human atrial and ventricular cells and our characterization of the rate and spatial characteristics of growth of these different cell types within the scaffold. With further development, it may be possible to use a combination of these cell types, seeded into a biodegradable mesh, to create a contractile nonthrombogenic graft that grows and remodels in the same fashion as the cardiac structure that it replaces.

\section{Methods \\ Cell preparation}

Fetal rat cell isolation and culture. All animal procedures were carried out in compliance with the "Guide for the care and use of laboratory animals" prepared by the Institute of Laboratory Animal Resources and published by the National Institutes of Health. Timed, pregnant, inbred Lewis rats (Charles River, Montreal, Canada) were anesthetized with an intramuscular injection of ketamine ( $22 \mathrm{mg} / \mathrm{kg}$ body weight) and killed with an intrathoracic injection of a combination of sodium pentobarbital and propylene glycol (Euthanyl; $2 \mathrm{~mL} /$ $4.25 \mathrm{~kg}$ body weight; MTC Pharmaceuticals, Cambridge, Ontario, Canada). For isolation of ventricular cells, the fetal rat hearts (19 days' gestation) were rinsed 3 times with phosphate-buffered saline solution (PBS; $\mathrm{NaCl} 136.9 \mathrm{mmol} / \mathrm{L}$, $\mathrm{KCl} 2.7 \mathrm{mmol} / \mathrm{L}, \mathrm{Na}_{2} \mathrm{HPO}_{4} 8.1 \mathrm{mmol} / \mathrm{L}$, and $\mathrm{KH}_{2} \mathrm{PO}_{4} 1.5$ $\mathrm{mmol} / \mathrm{L}$ [pH 7.4]). The blood clots, blood vessels, connective tissue, and atria were removed. The ventricles were rinsed in PBS 3 times and minced into pieces smaller than $1 \mathrm{~mm}^{3}$ in size. Fetal rat smooth muscle cells were obtained from the stomach, and portions of skin were used to obtain fibroblasts.

The tissue was transferred to a tube containing a mixed enzyme solution $(0.2 \%$ trypsin, $0.1 \%$ collagenase, and $0.02 \%$ glucose) and incubated at $37^{\circ} \mathrm{C}$ for 20 minutes. The enzyme solution containing the digested tissue was neutralized with an equal volume of culture medium (Iscove's modified Dulbecco's medium [IMDM]) supplemented with $10 \%$ fetal bovine serum, $0.1 \% \beta$-mercaptoethanol $(0.1 \mathrm{mmol} / \mathrm{L})$, and
$1 \%$ penicillin $(100 \mathrm{U} / \mathrm{mL})$ and streptomycin $(100 \mu \mathrm{g} / \mathrm{mL}) .^{5-7}$ Clumps of cells suspended in solution were dispersed by repeated pipetting. The cell suspension was centrifuged at $580 g$ for 5 minutes. The supernatant was discarded, and the cell pellet was resuspended in culture medium. A preplating technique was used to either enrich or deplete the cell suspension of fibroblasts, taking advantage of their differential adhesion characteristics. The cell suspension was then divided into 4 to 6 cell-culture dishes $(10 \mathrm{~cm}$ in diameter), and IMDM was added to each of the dishes to a total volume of $11 \mathrm{~mL}$. Cells were cultured at $37^{\circ} \mathrm{C}$ in $5 \% \mathrm{Co}_{2}$ and $95 \%$ air.

Cultured cells were identified by immunohistochemistry. Cultures of fetal rat ventricular cardiomyocytes were stained with antibodies against troponin I. Purity of the cardiomyocyte culture was $96 \% \pm 3 \%$. Smooth muscle cell cultures underwent staining with antibodies directed against smooth muscle cell actin, with a purity of $88 \% \pm 6 \%$. Fibroblast cultures were examined microscopically, and spindle-shaped cells of the anticipated morphology were presumed to be fibroblasts. The purity of the fibroblast cultures was $92 \% \pm 5 \%$.

Adult human atrial and ventricular cell isolation and culture. Adult patients undergoing coronary artery bypass surgery gave informed consent under a protocol approved by our institutional research ethics committee and had a small portion of the right atrial appendage excised for isolation and culture of atrial cells. A Tru-Cut needle (Allegiance Healthcare Corporation, McGaw Park, Ill) was also used to obtain a full-thickness core biopsy specimen of the anterior wall of the left ventricle in an area of grossly normal-appearing myocardium. Cell preparation, isolation, and culture were performed $^{5-7}$ as described for the rat, except that the debris from the initial digestion was subjected to 2 more cycles of digestion with trypsin and collagenase. Briefly, the tissue was digested in enzyme solution $(0.2 \%$ trypsin, $0.1 \%$ collagenase, and $0.02 \%$ glucose) at $37^{\circ} \mathrm{C}$ for 20 minutes before neutralization with IMDM, containing $10 \%$ fetal bovine serum, $0.1 \% \beta$-mercaptoethanol $(0.1 \mathrm{mmol} / \mathrm{L})$, and $1 \%$ penicillin $(100 \mathrm{U} / \mathrm{mL})$ and streptomycin $(100 \mu \mathrm{g} / \mathrm{mL}) .^{5-7}$ The cell suspension was removed after each cycle, and fresh enzyme solution was added to the remaining tissue pellet for each additional cycle. The 3 aliquots of cell suspension were combined, centrifuged, and then resuspended in fresh medium for culturing. Preplating was used to deplete the cell suspension of fibroblasts. Cultures were maintained, as previously described, ${ }^{5-7}$ and were confluent 2 weeks after seeding and again 1 week after splitting the initial plates.

Cultures of adult human atrial and ventricular cardiomyocytes were stained with antibodies against troponin I for identification. The purity of our human atrial cardiomyocyte cultures by this immunohistochemical method was $85 \% \pm 4 \%$, and that of the ventricular cardiomyocytes was $89 \% \pm 3 \%$.

Cell harvesting for seeding. After isolation, the fetal rat cardiomyocytes, smooth muscle cells, and fibroblasts were cultured for 24 hours before use in preparation of the graft. Human atrial and ventricular cells were passaged 3 to 4 times before further use. At the time of cell harvesting, the cell culture medium was discarded, and the dishes were rinsed 3 
times with PBS. Trypsin solution, $1 \mathrm{~mL}(0.05 \%)$, with ethylenediamine tetraacetic acid $(2 \mu \mathrm{L} / \mathrm{mL})$ was added to each of the dishes. The dishes were placed into the incubator for 2 to 3 minutes. Cell culture medium, $2 \mathrm{~mL}$, was added to the dishes to stop the digestion. After being pipetted, the cell suspension was collected in a $50-\mathrm{mL}$ tube. The cell number was determined with a cell counter (Coulter Electronics Ltd, England). The tube containing the cell suspension was centrifuged for 5 minutes at $580 \mathrm{~g}$. After removal of the supernatant, the cell pellet was resuspended in a small volume of culture medium $\left(4 \times 10^{7}\right.$ cells $\left./ \mathrm{mL}\right)$.

Cell growth curves. Growth curves of cultured cells within the Gelfoam meshes (The Upjohn Company, Kalamazoo, Mich) were constructed for fetal rat ventricular cells, smooth muscle cells, fibroblasts, adult human atrial cells, and adult human ventricular cells. A large Gelfoam mesh was cut into multiple $4 \times 10 \times 10-\mathrm{mm}$ segments, each of which was seeded with an identical aliquot of cells, slowly distributing the cell suspension over the top surface of the Gelfoam cube. After 30 minutes, $5 \mathrm{~mL}$ of culture medium was carefully added along the side of the patch. Two hours later, more medium was added to submerge the patch completely. Grafts were incubated at $37^{\circ} \mathrm{C}$ in $5 \%$ carbon dioxide and $95 \%$ air, and medium was changed every 2 days. At each time point, Gelfoam grafts were completely digested, and the cells within the graft were counted ( $n=2$ grafts per time point). Each graft was washed with PBS and digested with $7 \mathrm{~mL}$ of PBS solution containing $0.1 \%$ collagenase $(273 \mathrm{U} / \mathrm{mg}$, type II), stirring until the Gelfoam mesh was completely digested (about 5 to 8 minutes). When digestion of the Gelfoam mesh was complete, the reaction was stopped by the addition of 5 $\mathrm{mL}$ of culture medium. After centrifugation at $600 \mathrm{~g}$ for 5 minutes, the pellet was immersed in $1 \mathrm{~mL}$ of $0.05 \%$ trypsin. This suspension was incubated for 1 minute at $37^{\circ} \mathrm{C}$ before the addition of $9 \mathrm{~mL}$ of culture medium. The cell number was then counted in duplicate with a cell counter (Coulter Electronics), and the cell growth curve was plotted.

Preparation of patches for cell seeding and histology. Gelfoam patches of varying dimensions and thicknesses were created. The patches were (1) $10 \times 10 \times 4 \mathrm{~mm}$, (2) $15 \times 15 \times$ $2 \mathrm{~mm}$, or $(3) 15 \times 15 \times 1 \mathrm{~mm}$. The patches were presoaked in culture medium and then compressed on a sterile cloth to remove excess medium. Each patch was then placed in a 10$\mathrm{cm}$ culture dish for cell seeding.

Seeding of the Gelfoam patches. Different types of cultured fetal rat cells were seeded into Gelfoam patches by a variety of techniques to study their 3-dimensional growth characteristics within the matrix.

Injection method. The cell suspension was injected into the center of a $10 \times 10 \times 4-\mathrm{mm}$ Gelfoam patch in a single location with a 25 -gauge needle.

Onlay and stacking method. The cell suspension was slowly and evenly distributed over the surface of a $15 \times 15 \times$ $1-\mathrm{mm}$ patch. After 1 to 2 weeks of initial culture, 2 to 3 patches were stacked together. The seeded surfaces of the first and second patches were placed in apposition, and the seeded surface of the third patch was placed against the unseeded surface of the second patch. These stacked Gelfoam patches were then cultured together in culture medium.

Double onlay and stacking method. The cell suspension was distributed over the surface of either a $15 \times 15 \times 1-\mathrm{mm}$ patch or a $15 \times 15 \times 2-\mathrm{mm}$ patch. Two days later, the seeded patch was flipped over, and the other surface of the patch was seeded in the same fashion, with an identical number of cells. After 1 to 2 weeks of initial culture, 2 to 3 of these doubly seeded patches were stacked together and then cultured together in a sufficient depth of culture medium to keep the stack completely submerged.

Histologic analysis. Each graft was washed with PBS and fixed in a $37 \%$ solution of formaldehyde for 2 days. The grafts were then cut in half along the center of the patch, embedded in paraffin, and sectioned to yield $10-\mu \mathrm{m}$ thick specimens. Sections were stained with hematoxylin and eosin stain as described in the manufacturer's specifications (Sigma Diagnostics, St Louis, Mo).

\section{Results}

Growth curves. The growth curves of fetal rat ventricular cardiomyocytes, stomach smooth muscle cells, skin fibroblasts, and adult human atrial and ventricular cardiomyocytes within the Gelfoam grafts are presented in Fig 1, A-E. The fetal rat cardiomyocytes and smooth muscle cells demonstrated steady proliferation over the course of these experiments. Fetal rat fibroblasts also grew gradually within the matrix, but we noted much more rapid shrinkage and degradation of the Gelfoam block and gradual and progressive transfer of the fibroblasts onto the surface of the underlying culture dish. Adult human atrial cardiomyocytes proliferated within the Gelfoam patch but at a significantly slower rate than that noted in the fetal rat cardiomyocytes. Adult human ventricular cardiomyocytes survived within the Gelfoam matrix but did not appear to increase in number during the 2-week duration of evaluation. Gelfoam meshes seeded with the fetal rat ventricular cells exhibited spontaneous rhythmic contractility with movement of the Gelfoam patch. No such spontaneous activity was noted, however, in grafts seeded with adult human atrial or ventricular cardiomyocytes.

Fate of the Gelfoam matrix. The Gelfoam matrix gradually decreased in size after being seeded with the varying cell types and maintained in tissue culture. Four weeks after cell seeding, the Gelfoam matrix was $80 \% \pm 5 \%$ of its original surface area, except after seeding with fetal rat skin fibroblasts, which resulted in significantly more rapid degradation of the matrix $(50 \% \pm 3 \%)$.

\section{Three-dimensional growth characteristics}

Injection method. For fetal rat ventricular cardiomyocytes, despite the cells being injected into the center of 

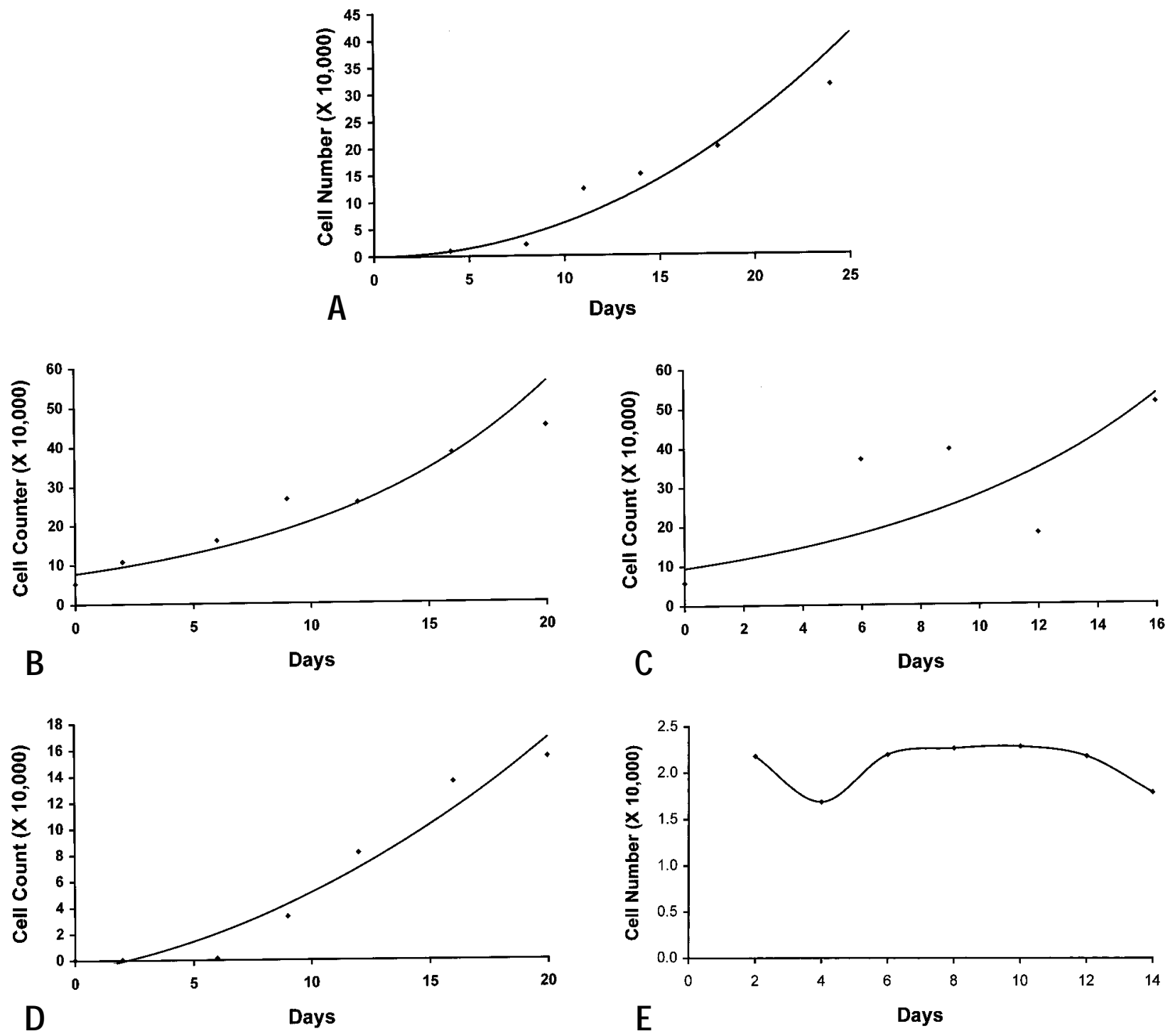

Fig 1. Growth curves of varying cell types after seeding onto a Gelfoam matrix and maintenance in tissue culture: fetal rat cardiomyocytes (A), fetal rat gastric smooth muscle cells (B), fetal rat skin fibroblasts (C), adult human atrial cardiomyocytes (D), and adult human ventricular cardiomyocytes (E). All cell types proliferated after seeding into the Gelfoam matrix except for the adult human ventricular cardiomyocytes, which survived but did not increase in number. Fetal rat cells proliferated more rapidly than adult human atrial cardiomyocytes.

the 4-mm thick Gelfoam patch at both 2 and 6 weeks after seeding, viable cardiomyocytes were essentially found only on the upper surface of the Gelfoam block (Fig 2). The cardiomyocytes had proliferated over the entire surface area of the patch but were confined to the uppermost $300 \mu \mathrm{m}$ of the thickness of the patch. A small number of viable cells was noted at the center of the patch near the original injection site, along with some cellular debris likely representing the remnants of necrotic cells.
For fetal rat gastric smooth muscle cells, 2 and 6 weeks after injection into the center of the Gelfoam patch, the smooth muscle cells had also migrated to the uppermost surface of the patch, where they had proliferated to cover its entire surface area (Fig 3). The depth of this layer of cells was approximately $300 \mu \mathrm{m}$. Again, a small number of smooth muscle cells and some necrotic cellular debris was noted in the center of the patch.

For fetal rat skin fibroblasts, 2 weeks after injection 


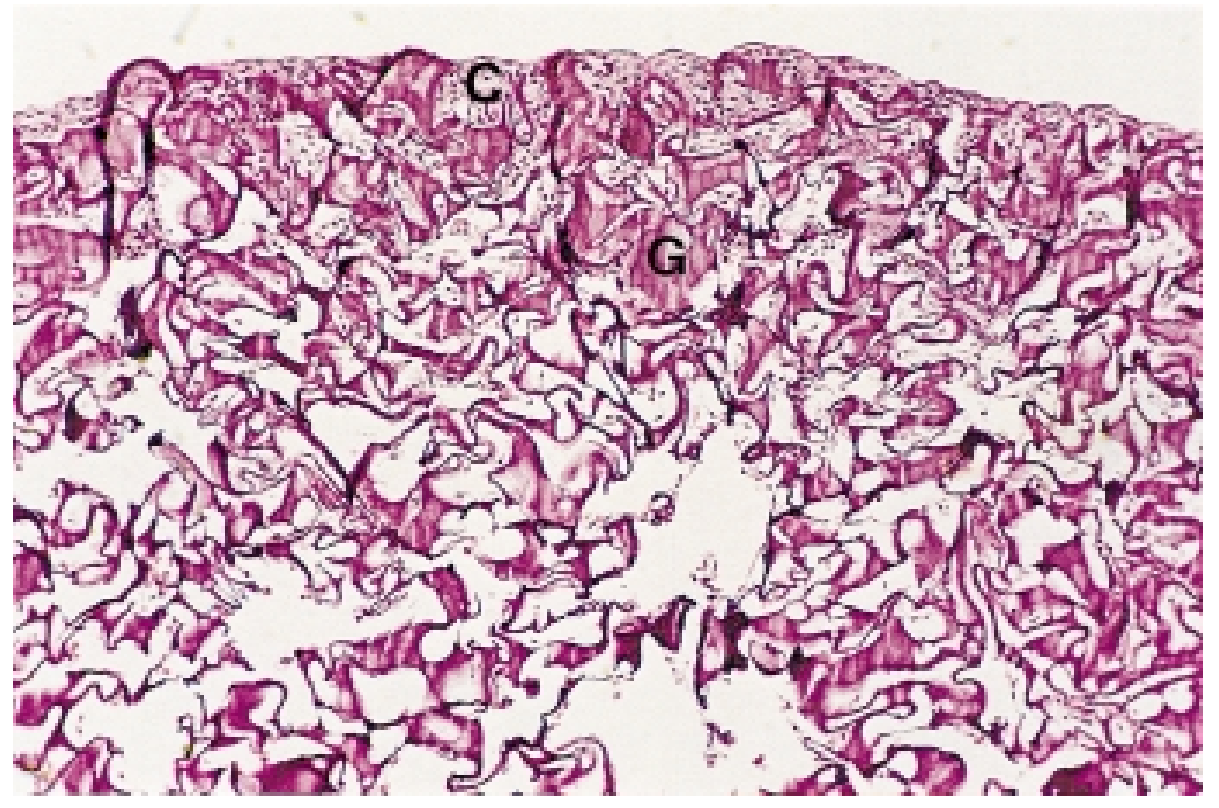

Fig 2. A gelatin mesh $(G) 2$ weeks after injection of fetal rat ventricular cardiomyocytes into the center of the mesh. The cardiomyocytes $(C)$ had migrated to the uppermost surface of the mesh to form a layer approximately $300 \mu \mathrm{m}$ thick. (Hematoxylin and eosin stain; original magnification 100×.)

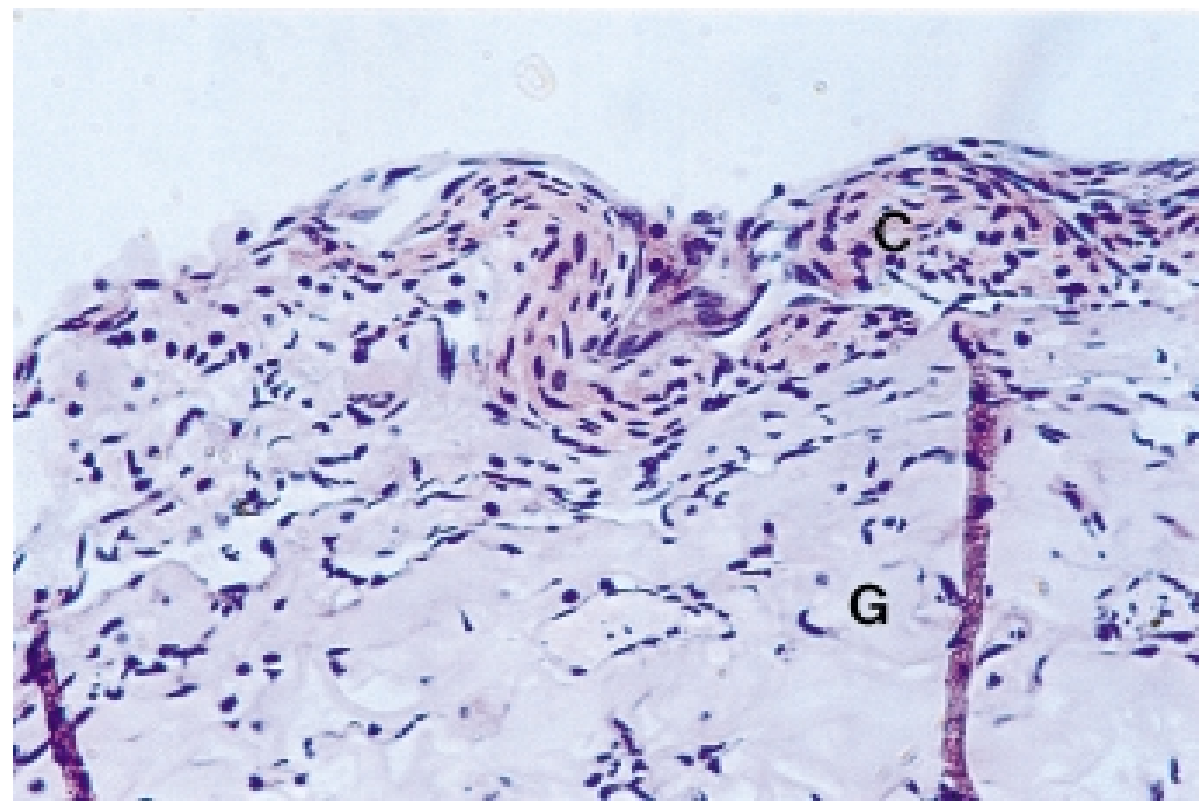

Fig 3. A gelatin mesh $(G) 2$ weeks after injection of fetal rat stomach smooth muscle cells into the center of the mesh. The smooth muscle cells $(C)$ had migrated to the uppermost surface of the mesh, forming a layer approximately $300 \mu \mathrm{m}$ in thickness. (Hematoxylin and eosin stain; original magnification $200 \times$.)

of the fibroblast suspension, we noted a $500-\mu \mathrm{m}$ thick layer of viable fibroblasts on the uppermost surface of the patch (Fig 4). Within this layer, we noted several hair follicle-like structures. As previously described, the Gelfoam mesh was rapidly degraded by the fibroblasts. Six weeks after injection, we noted only a thin layer of fibroblasts remaining in the center of the patch. Onlay and stacking method. For fetal rat ventricular 


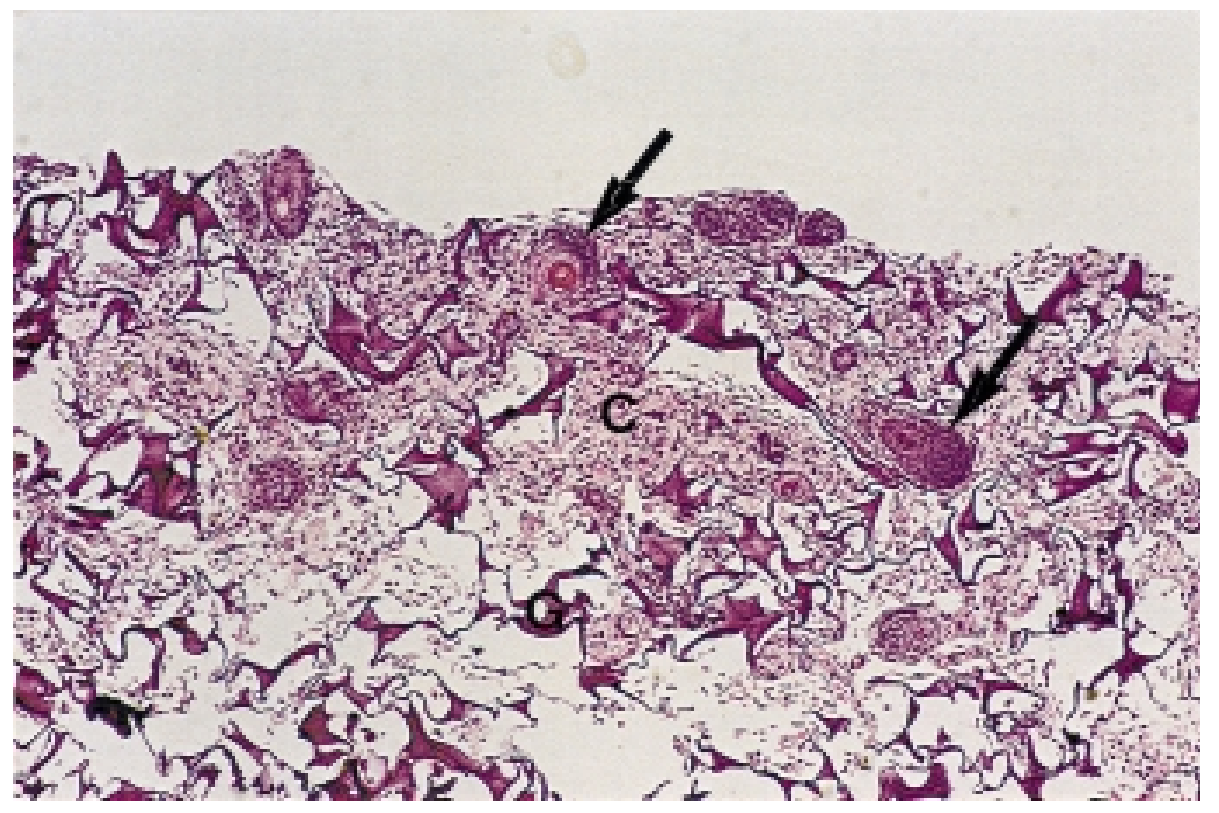

Fig 4. A gelatin mesh $(G) 2$ weeks after injection of a suspension of fetal rat skin fibroblasts into the center of the mesh. The fibroblasts $(C)$ had formed a layer approximately $500 \mu \mathrm{m}$ thick on the upper surface of the patch, in which were noted several hair follicles (arrows). (Hematoxylin and eosin stain, original magnification 100×.)

cardiomyocytes, 1 week after the ventricular cardiomyocytes were delivered onto the surface of 3 Gelfoam patches and the patches were stacked together, the uppermost patch showed even, full-thickness growth of viable cells (Fig 5). The cells in the second and third Gelfoam patches below, however, were starting to necrose, with many of the cells demonstrating nuclear lysis. After 4 weeks in culture, the patches were essentially unchanged, with cardiomyocyte survival noted almost exclusively in the top patch.

When only 2 patches (each $1 \mathrm{~mm}$ in thickness) were seeded and stacked together, with their seeded surfaces in apposition, the cells migrated to the uppermost and lowermost surfaces. Three and four weeks after stacking, very few viable cells remained at the interface of the 2 patches. The layer of cardiomyocytes on the uppermost surface of the stacked patches was noticeably thicker than the layer on the lowermost surface, which was in contact with the Petri dish.

\section{Discussion}

Tissue engineering and transplantation has been studied for many years in several organ systems. ${ }^{8-12}$ However, the development of a tissue-engineered, cellseeded graft material with potential applications in repair of congenital or acquired cardiac defects has remained a difficult process. Issues that have yet to be definitively settled include the selection of an appropriate substrate for seeding with viable cells, the source and optimal combination of cells to be seeded, the technique by which to ensure that the seeded cells organize in a manner that is structurally appropriate for the intended use of the graft, and the short- and long-term characteristics of these grafts after implantation. ${ }^{13-17}$

Our laboratory has used a Gelfoam gelatin mesh as a biodegradable scaffold to support the 3-dimensional growth of seeded cells. We have previously characterized the behavior of these grafts in tissue culture after seeding with fetal rat ventricular cells and in vivo after implantation into either the subcutaneous tissue of adult rats or onto the left ventricular free wall 4 weeks after myocardial scarring induced by cryoinjury. ${ }^{4}$ These cells proliferated within the mesh, but only to a limited degree when maintained in tissue culture, prompting us to investigate the rate of proliferation and the 3-dimensional growth characteristics of a variety of fetal rat and adult human cell types in this gelatin mesh.

We have previously noted variable rates of proliferation of rat and human cardiomyocytes in a monolayer on a culture plate. ${ }^{6,18}$ These cells proliferate to confluence and then cease further division unless the cultures are split. ${ }^{6}$ In the 3-dimensional matrix of Gelfoam mesh used in our present study, we observed that fetal rat cardiomyocytes grew steadily over a 4-week period, 


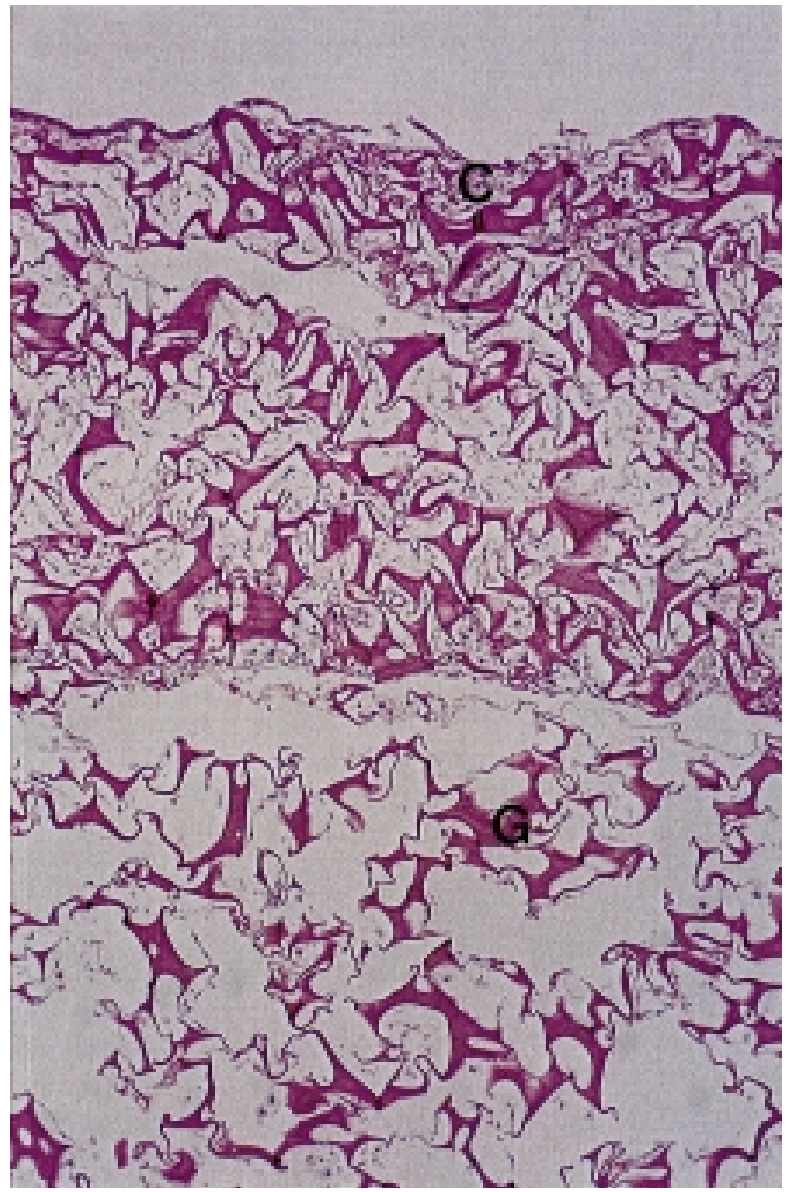

Fig 5. Gelatin mesh grafts that had been stacked together after seeding of one surface on each graft with fetal rat ventricular cardiomyocytes and maintenance in tissue culture for 1 week. The cells occupied the full thickness of the topmost gelatin mesh, but only scattered cells were noted in the second and third meshes below. (Hematoxylin and eosin stain, original magnification $100 \times$.)

as did fetal rat smooth muscle cells and fibroblasts. Adult human atrial cardiomyocytes also proliferated at a steady pace, although more slowly than the fetal rat cells. The adult human ventricular cardiomyocytes survived within the Gelfoam matrix, but their numbers did not increase over a 2-week period. The reason for the different activities of human atrial and ventricular cardiomyocytes is unclear. We are continuing these experiments and plan to evaluate grafts seeded with cardiomyocytes obtained from pediatric patients and to determine the relative effects of donor age on cell proliferation within these grafts.

In this study we noted that even cells delivered by means of injection in a single bolus into the middle of a block of Gelfoam mesh preferentially migrated over the course of a week to the uppermost surface of the patch. All cell types examined formed a layer on this uppermost surface, which was consistently 300 to 500 $\mu \mathrm{m}$ in thickness. The depth of this cell layer may have been due to the limitation of passive diffusion through the culture medium for delivery of nutrients and removal of metabolites from these cells. This might also account for the necrosis of a significant fraction of the cells injected in one bolus into the center of the Gelfoam patch.

We noted that the thickness of the layers of fetal rat cardiomyocytes was approximately $300 \mu \mathrm{m}$, somewhat less than that noted for fibroblasts. We speculate that the rhythmic contractile activity of the fetal rat cardiomyocytes might have accentuated the limitations of passive diffusion for metabolic support of these cells, resulting in a thinner layer of viable cells. Other potential mechanisms may, however, also contribute to this limitation of cell growth. A cell-signaling phenomenon may have contributed to the cessation of proliferation at 300 to $500 \mu \mathrm{m}$, although the mechanism by which this occurs may differ from the usual process of contact inhibition noted when these cells are grown in a monolayer.

We are conducting ongoing studies in an attempt to clarify the determinants of cell proliferation, linkage, and contractile activity within these biodegradable cellseeded gelatin mesh grafts. It may ultimately become possible to obtain cells from endomyocardial biopsy specimens in children with congenital heart disease in whom palliation or repair can be anticipated to require a prosthetic patch or conduit. Expansion of these cells in culture and seeding of an appropriately shaped and sized biodegradable mesh may allow subsequent surgical implantation of a graft with growth potential and perhaps lower thrombogenicity, reducing the late morbidity and mortality that follow even initially successful surgical correction of congenital heart disease. Niklason and colleagues ${ }^{19}$ have recently reported the construction of vascular grafts containing smooth muscle cells and endothelial cells that demonstrate promise for use in peripheral vascular reconstruction. In preliminary experiments we have also successfully implanted a cardiomyocyte-seeded gelatin mesh graft as a patch replacement for the right ventricular outflow tract in rats. Further studies to determine the medium-term fate of these grafts are continuing.

\section{REFERENCES}

1. Hoffman J. Incidence of congenital heart disease: II. Prenatal incidence. Pediatr Cardiol 1995;16:155-65.

2. Kirklin J, Barratt-Boyes B. Ventricular septal defect and pulmonary stenosis or atresia. In: Kirklin J, Barratt-Boyes B, editors. 
Cardiac surgery. 2nd ed. New York: Churchill Livingstone; 1993. p. 885-919.

3. Kirklin J, Barratt-Boyes B. Ventricular septal defect and pulmonary stenosis or atresia. In: Kirklin J, Barratt-Boyes B, editors. Cardiac surgery. 2nd ed. New York: Churchill Livingstone; 1993. p. 964-7.

4. Li R-K, Jia Z-Q, Weisel RD, et al. Survival and function of bioengineered cardiac grafts [abstract]. Circulation 1998;98(Suppl): I748.

5. Li R-K, Mickle DAG, Weisel RD, et al. The natural history of fetal rat cardiomyocytes transplanted into adult rat myocardial scar tissue. Circulation 1997;96(Suppl):II179-87.

6. Li R-K, Mickle DAG, Weisel RD, et al. Human pediatric and adult ventricular cardiomyocytes in culture: assessment of phenotypic changes with passaging. Cardiovasc Res 1996;32:362-73.

7. Li R-K, Weisel RD, Williams WG, Mickle DAG. Method of culturing cardiomyocytes from human pediatric ventricular myocardium. J Tiss Cult Meth 1992;14:93-100.

8. Pollok J-M, Vacanti JP. Tissue engineering. Semin Pediatr Surg 1996;5:191-6.

9. Nathan A, Nugent MA, Edelman ER. Tissue engineered perivascular endothelial cell implants regulate vascular injury. Proc Natl Acad Sci U S A 1995;92:8130-4.

10. Park SS, Ward MJ. Tissue-engineered cartilage for implantation and grafting. Facial Plastic Surg 1995;11:278-83.

11. Daniels E. Ultrastructural observations on the three-dimensional reorganization and growth of newly-formed candidate stromal cells and residual hemopoietic cells in culture. Exp Hematol 1980;8:157-65.

12. Okano T, Matsuda T. Tissue engineered skeletal muscle: preparation of highly dense, highly oriented hybrid muscular tissues. Cell Transplant 1998;7:71-82.

13. Eschenhagen T, Fink C, Remmers U, et al. Three-dimensional reconstitution of embryonic cardiomyocytes in a collagen matrix: a new heart muscle model system. FASEB J 1997;11:683-94.

14. Vanwinkle WB, Snuggs MB, Buja LM. Cardiogel: a biosysthetic extracellular matrix for cardiomyocyte culture. In Vitro Cell Dev Biol Anim 1996;32:478-85.

15. Leighton J. A sponge matrix method for tissue culture. Formation of organized aggregates of cells in vitro. J Natl Cancer Inst 1951; 12:545-61.

16. Souren JEM, Schneijdenberg C, Verkleij AJ, Van Wijk R. Factors controlling the rhythmic contraction of collagen gels by neonatal heart cells. In Vitro Cell Dev Biol 1992;28A:199-204.

17. Sittinger M, Bujia J, Rotter N, Reitzel D, Minuth WW, Burmester GR. Tissue engineering and autologous transplant formation: practical approaches with resorbable biomaterials and new cell culture techniques. Biomaterials 1996;17:237-42.

18. Li R-K, Jia Z-Q, Weisel RD, et al. Cardiomyocyte transplantation improves heart function. Ann Thorac Surg 1996;62:654-61.
19. Niklason LE, Gao J, Abbott WM, et al. Functional arteries grown in vitro. Science 1999;284:489-93.

\section{Discussion}

Dr Yoshiki Sawa (Osaka, Japan). I would like to ask 2 questions. First, how long can these cells survive? How long can these cells survive in this mesh? And during its survival, how was the change of the phenotype? Did it change the phenotype?

Second question, how was the blood supply in the mesh? Did you check the blood vessels?

Dr Li. We evaluated cell survival and proliferation in vitro for as long as 14 days, and the cells survived within the graft during this period. We are currently investigating the possibility of phenotypic changes of these cells in the graft by using immunohistochemistry and Northern and Western blots to evaluate contractile protein levels.

Because this is an in vitro study, we did not find blood vessels within the graft in culture. However, our previous studies have shown blood vessels growing into the grafts when the cell-seeded grafts were transplanted into the subcutaneous tissue of adult rats.

Dr Alain F. Carpentier (Paris, France). I have 2 brief questions. First, you mentioned human heart cells. Were these cells fetal cells or adult cells?

One problem you could encounter with this technique is fibroblast proliferation coming from the host. Have you seen some fibroblast proliferation, or was your time of observation too short to see that? What do you think about this potential problem?

Dr Li. The atrial and ventricular cells were isolated from the myocardium of adult patients. The cells were seeded in culture dishes at low density, and cardiac muscle cells were purified and cultured in IMDM medium. There were few fibroblasts in the culture after purification. Although the number of these fibroblasts increased with time, in early passages $(<4)$ most cells in these cultures expressed contractile proteins, which were identified by using a monoclonal antibody against troponin I and appeared to be cardiac muscle cells. Although the cell number increased in a monolayer in the culture plates, they did not proliferate further after being seeded into the grafts. Therefore, myocardial fibroblasts could not overgrow the graft.

Our immunohistochemical studies demonstrated that these cells have contractile proteins, although they did not contract. We believe that stretch may be necessary to induce organization of these contractile proteins into myofilaments. 